\title{
Theoretical Study on the Reaction Mechanism of Azacyclopropenylidene with Epoxypropane: An Insertion Process
}

\author{
Xiaojun Tan, ${ }^{*}$ Weihua Wang, ${ }^{\dagger}$ and Ping $\mathrm{Li}^{\dagger+, *}$ \\ College of Biological Science and Technology, University of Jinan, Jinan, Shandong 250022, People's Republic of China \\ *E-mail: chm_tanxj@ujn.edu.cn \\ ${ }^{\dagger}$ School of Chemistry and Chemical Engineering, Qufu Normal University, Qufu, Shandong 273165, \\ People's Republic of China. *E-mail: lpsdu@sdu.edu.cn \\ Received February 3, 2014, Accepted May 16, 2014
}

\begin{abstract}
The reaction mechanism between azacyclopropenylidene and epoxypropane has been systematically investigated employing the second-order Møller-Plesset perturbation theory (MP2) method to better understand the reactivity of azacyclopropenylidene with four-membered ring compound epoxypropane. Geometry optimization, vibrational analysis, and energy property for the involved stationary points on the potential energy surface have been calculated. It was found that for the first step of this reaction, azacyclopropenylidene can insert into epoxypropane at its $\mathrm{C}-\mathrm{O}$ or $\mathrm{C}-\mathrm{C}$ bond to form spiro intermediate IM. It is easier for the azacyclopropenylidene to insert into the $\mathrm{C}-\mathrm{O}$ bond than the $\mathrm{C}-\mathrm{C}$ bond. Through the ring-opened step at the $\mathrm{C}-\mathrm{C}$ bond of azacyclopropenylidene fragment, IM can transfer to product $\mathrm{P} 1$, which is named as pathway (1). On the other hand, through the H-transferred step and subsequent ring-opened step at the C-N bond of azacyclopropenylidene fragment, IM can convert to product P2, which is named as pathway (2). From the thermodynamics viewpoint, the P2 characterized by an allene is the dominating product. From the kinetic viewpoint, the pathway (1) of formation to $\mathrm{P} 1$ is primary.
\end{abstract}

Key Words : Azayclopropenylidene, Epoxypropane, Reaction mechanism, Molecular orbital

\section{Introduction}

Carbon chain molecules containing heteroatoms $\left(\mathrm{N},{ }^{1-8}\right.$ $\mathrm{O},{ }^{9,10} \mathrm{~S},{ }^{11-13} \mathrm{Si}^{14-16}$ ) have been paid much attention recently due to their astrophysical abundance and interesting spectroscopic properties. A typical example is cyanopolyacetylenes $\mathrm{HC}_{2 \mathrm{n}+1} \mathrm{~N}$, in which $\mathrm{HC}_{11} \mathrm{~N}$ is one of the largest carbon chain molecules observed in interstellar medium. ${ }^{17}$ In contrast to cyanopolyacetylenes $\mathrm{HC}_{2 \mathrm{n}+1} \mathrm{~N}$, systematic studies on the molecules $\mathrm{HC}_{2 \mathrm{n}} \mathrm{N}$ containing even number of carbon atoms were relatively scarce. In spite of this, the $\mathrm{HC}_{2 \mathrm{n}} \mathrm{N}$ molecules and their geometrical isomers are still very important species of astrophysical importance, where they are good candidates for astrophysical observation by microwave and infrared spectroscopy due to the rather large dipole moments of these molecules. What's exciting is that $\mathrm{HC}_{2} \mathrm{~N}$ has been observed in interstellar space. ${ }^{18} \mathrm{~A}$ lot of experimental and computational methods were carried out for the structures and the relative energies of some isomers of this system. Many studies have revealed that there are many isomers with different kinds of geometries (linear, bent or cyclic) or different multiplicities (singlet or triplet) having similar energies for the $\mathrm{HC}_{2} \mathrm{~N}$ molecules. ${ }^{19-30}$ Lee et al. have characterized the quasilinear triplet, bent singlet, and cyclic singlet $\mathrm{HC}_{2} \mathrm{~N}$ isomers and determined their molecular properties with a series of highly accurate $a b$ initio levels of theory. ${ }^{27}$ In addition, the cyclic $\mathrm{HC}_{2} \mathrm{~N}$ isomer was found to be an intermediate between the interconversion of the bent HCCN and the unknown bent $\mathrm{HCNC}$ on the hypersurface of neutral, anionic, and cationic species, where the barriers are feasible. ${ }^{31}$ For the most stable singlet state of $\mathrm{HC}_{2} \mathrm{~N}$ molecule, it has been displayed in Scheme 1, which has been confirmed by spectroscopy and calculation.

In 1998, matrix generations of singlet azacyclopropenylidene and singlet bromocyanocarbene $(\mathrm{BrCCN})$ were researched by Maier and co-workers. ${ }^{32}$ Casavecchia et al. reported the dynamics of a reaction of nitrogen atom with an unsaturated hydrocarbon by combining crossed molecular beam experiments and $a b$ initio molecular orbital calculations. They found that azacyclopropenylidene is one of the products of the reaction of nitrogen atom with $\mathrm{C}_{2} \mathrm{H}_{2}$ in the upper atmosphere of Titan. ${ }^{33}$ Thus, the azacyclopropenylidene seems to be a good candidate for astrophysical detection, considering these various possible formation pathways and its large dipole moment. ${ }^{34}$

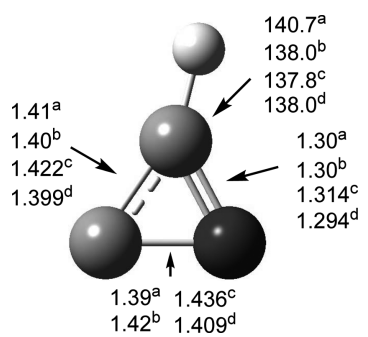

Scheme 1 Geometrical parameters for azacyclopropenylidene calculated at the diverse levels, where bond lengths are in $\AA$ and bond angles in degree ( ${ }^{\mathrm{a}}$ : B3LYP/6-311++G**28; b: MP2/6$311++\mathrm{G}^{* * 28}$; c: QCISD(T)/D95**21; d: CCSD(T)/cc-pVTZ ${ }^{30}$ ). 
Computation of $\mathrm{HC}_{2} \mathrm{~N}$ molecules will be very helpful to elucidate the reactivity and kinetic stability of these molecules, but less attention has been paid to the reactivity of azacyclopropenylidene with the active species containing small ring compounds until now. In the present study, we have performed comprehensive theoretical investigations of the reaction mechanism between azacyclopropenylidene and epoxypropane by employing the second-order MøllerPlesset perturbation theory (MP2) method in order to better understand the azacyclopropenylidene reactivity. To the best of our knowledge, this study is the first report of the reaction mechanism between azacyclopropenylidene and fourmembered ring compounds. The present results will enrich the available data for the relevant azacyclopropenylidene chemistry and discuss the possibility of formation of larger molecules by means of azacyclopropenylidene in interstellar space.

\section{Calculation Method}

The MP2 method and the $6-311+\mathrm{G}^{*}$ basis set have been employed to locate all the stationary points along the reaction pathways. Frequency analyses have been carried out to confirm the nature of the minima and transition states at the MP2/6-311+G* level of theory, i.e., all the reactants, intermediates, and products have been characterized by no imaginary frequency. Moreover, intrinsic reaction coordinate (IRC) calculations have also been performed to further validate the calculated transition states connecting reactants and products. Additionally, the relevant energy quantities, such as reaction energies and barrier heights, have been corrected with zero-point vibrational energy (ZPVE).

All the calculations have been performed using Gaussian 98 program. ${ }^{35}$

\section{Results and Discussion}

Azacyclopropenylidene can insert into epoxypropane at its C-O or C-C bond. For the sake of simplicity, we mainly discuss the reaction mechanisms based on the pathways of azacyclopropenylidene insertion into epoxypropane at its C$\mathrm{O}$ bond, which is marked with superscript "O". As for the pathways of insertion into $\mathrm{C}-\mathrm{C}$ bond, we mark it with superscript " $\mathrm{C}$ ".

As displayed in Scheme 2, four possible reaction pathways for the insertion reaction between azacyclopropenylidene and epoxypropane have been proposed. The geometric parameters for the reactants (azacyclopropenylidene (R1) and epoxypropane (R2)), transition states (TS), intermediates (IM), and products (P) involved in the pathways $\left({ }^{\mathrm{O}} 1\right),\left({ }^{\mathrm{O}} 2\right),\left({ }^{\mathrm{C}} 1\right)$, and $\left({ }^{\mathrm{C}} 2\right)$ are displayed in Figure 1. Correspondingly, the calculated relative energies for the available stationary points have been summarized in Table 1 . The corresponding reaction profile of the pathways $\left({ }^{\mathrm{O}} 1\right)$ and $\left({ }^{\mathrm{O}} 2\right)$ are illustrated in Figure 2. The reaction mechanisms of the pathways $\left({ }^{\mathrm{O}} 1\right)$ and $\left({ }^{\mathrm{O}} 2\right)$ are similar to the pathways $\left({ }^{\mathrm{C}} 1\right)$ and ( $\left.{ }^{\mathrm{C}} 2\right)$, respectively. For the sake of simplicity, the following

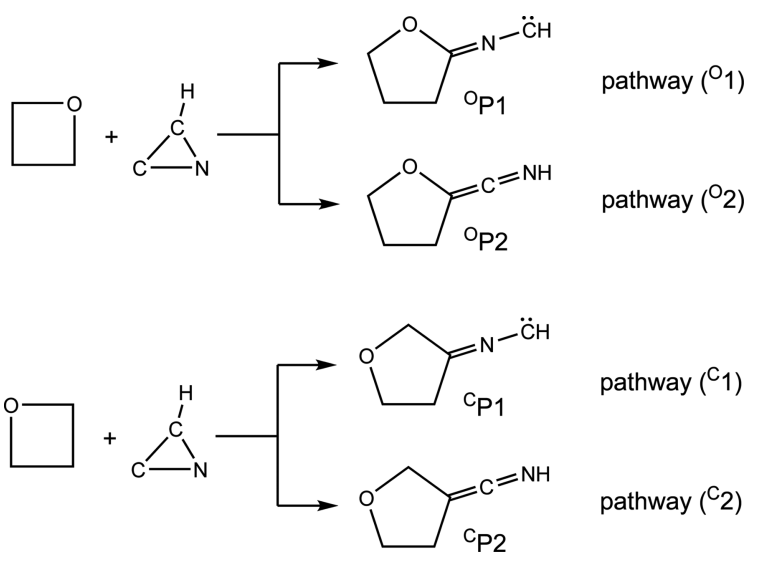

Scheme 2. The proposed four reaction pathways for the insertion reaction between azacyclopropenylidene and epoxypropane.

discussions are mainly based on the pathways $\left({ }^{\mathrm{O}} 1\right)$ and $\left({ }^{\mathrm{O}} 2\right)$.

Insertion Process to form Spiro Intermediate IM. The first intermediate ${ }^{\mathrm{O}} \mathrm{IM}$ in the reaction between azacyclopropenylidene and epoxypropane is formed via a barrier of $203.0 \mathrm{~kJ} / \mathrm{mol}$. The calculated unique imaginary frequency of the transition state ${ }^{\mathrm{O}} \mathrm{TS}$ in the insertion process is $629 \mathrm{icm}^{-1}$ at the MP2/6-311+G* level of theory.

As shown in Figure 1, in ${ }^{\mathrm{O}} \mathrm{TS}$, the distances of $\mathrm{C}^{1}-\mathrm{O}$ and $\mathrm{C}^{1}-\mathrm{C}^{5}$ are 2.049 and $2.208 \AA$, respectively. The distance of $\mathrm{O}-\mathrm{C}^{5}$ in $\mathrm{R} 2$ fragment of ${ }^{\mathrm{O}} \mathrm{TS}$ is elongated significantly to $1.950 \AA$. Thus, in the transition state ${ }^{\mathrm{O}} \mathrm{TS}$, two new bonds of $\mathrm{C}^{1}-\mathrm{O}$ and $\mathrm{C}^{1}-\mathrm{C}^{5}$ are to form and the $\mathrm{O}-\mathrm{C}^{5}$ bond is to break simultaneously. In other words, it's the process of $\mathrm{C}^{1}$ atom of $\mathrm{R} 1$ fragment insertion into the $\mathrm{O}-\mathrm{C}^{5}$ bond of $\mathrm{R} 2$ fragment that resulted in the formation of a spiro intermediate ${ }^{\mathrm{O}} \mathrm{IM}$. Moreover, as shown in Figure 3, those changes can be further validated by the IRC calculations on the basis of ${ }^{\mathrm{O}} \mathrm{TS}$. Similarly, azacyclopropenylidene can insert into epoxypropane at its $\mathrm{C}^{3}-\mathrm{C}^{4}$ to form a spiro intermediate ${ }^{\mathrm{C}} \mathrm{IM}$.

Qualitatively, we can explain the insertion process from the frontier molecular orbital theory since the frontier orbitals (e.g., HOMO) of a chemical species are very important to define their reactivity and determine the way in which the molecule interacts with other species. ${ }^{36}$ As displayed in Figure 4, the weak strength of C-C and C-O bonds can be reflected from the HOMO of epoxypropane. Obviously, all of them are characterized by the $\pi$ antibonding orbital. As for azacyclopropenylidene, the activity of $\mathrm{C}^{1}$ site can be reflected from the largest contributions on the $\mathrm{C}^{1}$ atom to the components of the whole HOMO. Therefore, $\mathrm{C}^{1}$ atom in azacyclopropenylidene can insert into the $\mathrm{C}-\mathrm{O}$ bond or the $\mathrm{C}-\mathrm{C}$ bond of epoxypropane. Furthermore, polarized $\mathrm{C}-\mathrm{O}$ bond is more active than the nonpolar $\mathrm{C}-\mathrm{C}$ bond. It is easier for azacyclopropenylidene to insert into the $\mathrm{C}-\mathrm{O}$ bond than it inserts into the $\mathrm{C}-\mathrm{C}$ bond of epoxypropane, which can be verified by the barrier high of this insertion process $(203.0$ and $235.0 \mathrm{~kJ} / \mathrm{mol}$ for the insertion into $\mathrm{C}-\mathrm{O}$ and $\mathrm{C}-\mathrm{C}$ bond, respectively.).

As displayed in Figure 1, in ${ }^{\mathrm{O}} \mathrm{IM}$, the $\mathrm{C}^{2}$ and $\mathrm{N}$ atoms adopt $s p^{2}$ hybridization. Compared with the isolated aza- 


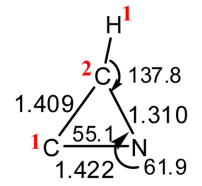

R1: azacyclopropenylidene

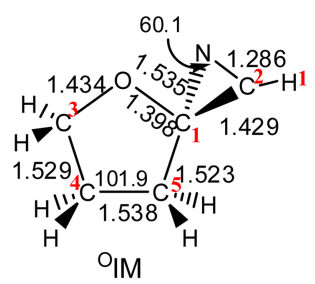

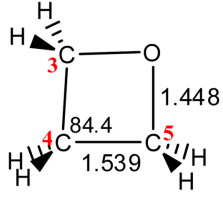

R2: epoxypropane

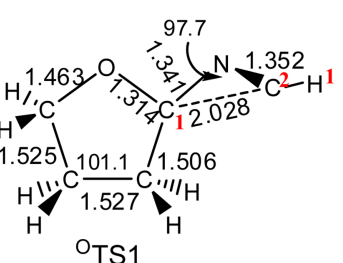

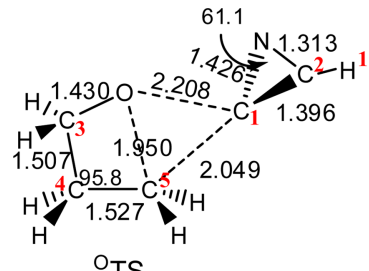

TS
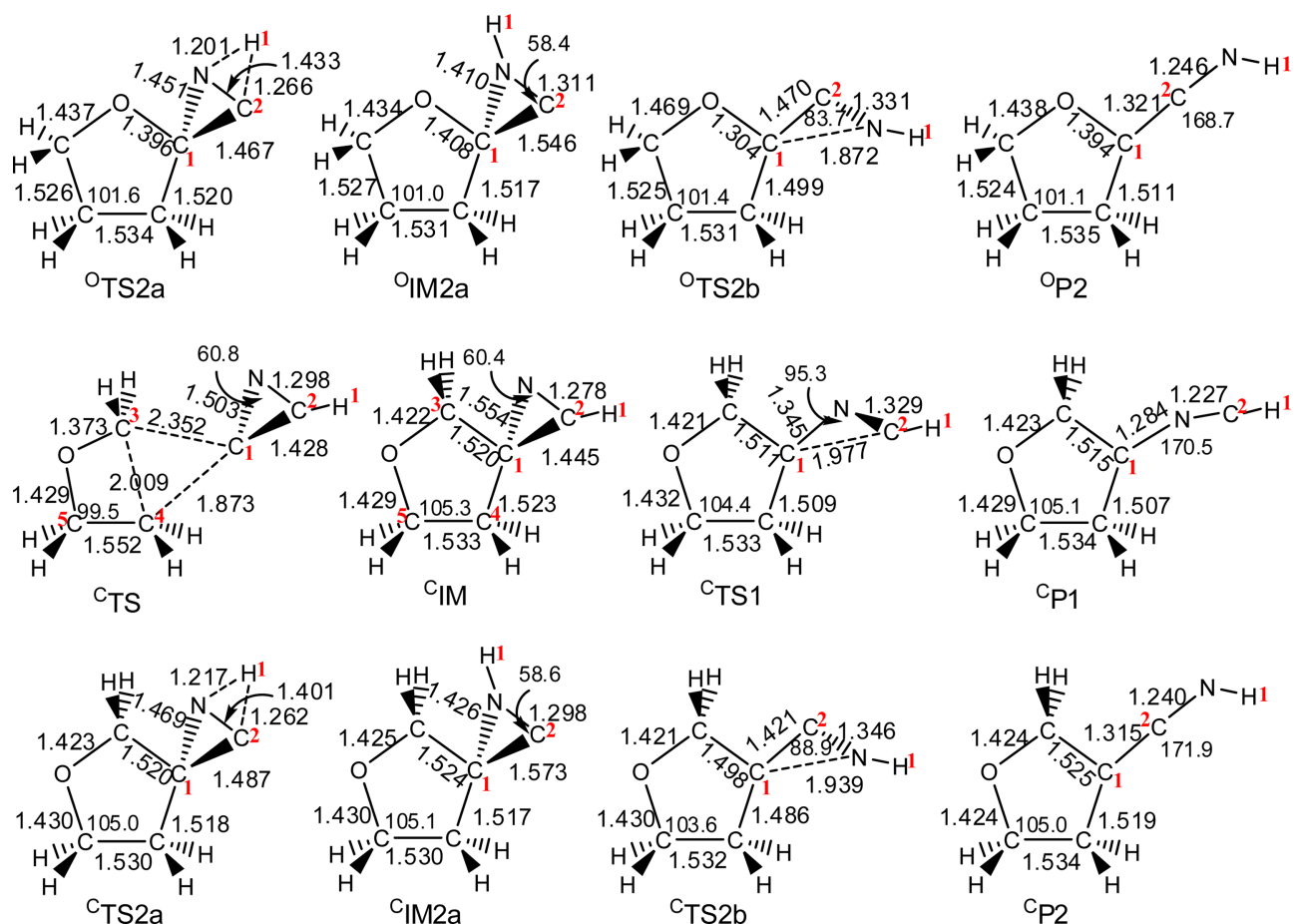

Figure 1. Optimized structures of the reactants (azacyclopropenylidene and epoxypropane), transition states (TS), intermediates (IM), and products $(\mathrm{P})$ in reaction pathways $\left({ }^{\mathrm{O}} 1\right),\left({ }^{\mathrm{O}} 2\right),\left({ }^{\mathrm{C}} 1\right)$, and $\left({ }^{\mathrm{C}} 2\right)$ at the MP2/6-311+G* level of theory, where the bond length and bond angle are in $\mathrm{nm}$ and degree, respectively.

Table 1. The calculated relative energy (in $\mathrm{kJ} / \mathrm{mol}$ ) with respect to the isolated reactants at the MP2/6-311+G* level of theory considering the ZPVE corrections

\begin{tabular}{|c|c|c|c|c|}
\hline Pathways & & Relati & nergies & \\
\hline & ${ }^{{ }^{O}} \mathrm{TS}$ & ${ }^{{ }^{O}} \mathbf{I M}$ & & \\
\hline & 203.0 & -350.1 & & \\
\hline Pathway $\left({ }^{\mathrm{O}} 1\right)$ & ${ }^{\mathrm{o}} \mathrm{TS} 1$ & ${ }^{\mathbf{o}} \mathbf{P 1}$ & & \\
\hline & -162.0 & -263.5 & & \\
\hline Pathway $\left({ }^{\mathrm{O}} 2\right)$ & ${ }^{\mathrm{O}} \mathrm{TS2a}$ & ${ }^{\mathrm{O}}$ IM2a & ${ }^{{ }^{\circ}}$ TS2b & ${ }^{\mathrm{o}} \mathbf{P} 2$ \\
\hline & $\begin{array}{c}-71.2 \\
{ }^{\mathbf{C}_{\mathbf{T S}}}\end{array}$ & $\begin{array}{c}-201.0 \\
\mathbf{C}_{\mathbf{I M}}\end{array}$ & -146.7 & -347.1 \\
\hline & 235.0 & -323.0 & & \\
\hline Pathway $\left({ }^{\mathrm{C}} 1\right)$ & ${ }^{{ }^{\mathrm{C}} \text { TS1 }}$ & ${ }^{\mathrm{C}} \mathbf{P 1}$ & & \\
\hline & -91.8 & -252.8 & & \\
\hline Pathway ( ${ }^{\mathrm{C}} 2$ ) & ${ }^{\mathrm{C}}$ TS2a & ${ }^{\mathrm{C}}$ IM2a & ${ }^{\mathrm{C}}$ TS2b & ${ }^{\mathrm{C}} \mathbf{P 2}$ \\
\hline & -43.1 & -179.3 & -54.7 & -364.2 \\
\hline
\end{tabular}

cyclopropenylidene, the bond length of $\mathrm{C}^{2}-\mathrm{N}$ in ${ }^{\mathrm{O}} \mathrm{IM}$ is shortened by $0.024 \AA$. The angle of $\mathrm{C}^{1} \mathrm{NC}^{2}$ in ${ }^{\mathrm{O}} \mathrm{IM}$ is $60.1^{\circ}$, which is decreased slightly by $1.8^{\circ}$ relative to that of the isolated azacyclopropenylidene. Therefore, the ring-tension of R1 fragment in ${ }^{\mathrm{O}} \mathrm{IM}$ is larger than that of the isolated R1. Because of the existed large tension in the three-membered ring, the $\mathrm{C}^{1}-\mathrm{C}^{2}$ bond in ${ }^{\mathrm{O}} \mathrm{IM}$ will open. Through the ringopened step at the $\mathrm{C}^{1}-\mathrm{C}^{2}$ bond, ${ }^{\mathrm{O}} \mathrm{IM}$ can convert to product ${ }^{\mathrm{O}} \mathrm{P} 1$, which is named as pathway $\left({ }^{\mathrm{O}} 1\right)$. On the other hand, through the H-transferred step and subsequent ring-opened step at the $\mathrm{C}-\mathrm{N}$ bond, ${ }^{\mathrm{O}} \mathrm{IM}$ can turn into product ${ }^{\mathrm{O}} \mathrm{P} 2$, which is named as pathway $\left({ }^{\mathrm{O}_{2}}\right)$. Therefore, ${ }^{\mathrm{O}} \mathrm{IM}$ is the common intermediate for the pathway $\left({ }^{\mathrm{O}} 1\right)$ and pathway $\left({ }^{\mathrm{O}} 2\right)$. Similarly, ${ }^{\mathrm{C}} \mathrm{IM}$ is the common intermediate for the pathway $\left({ }^{\mathrm{C}} 1\right)$ and pathway $\left({ }^{\mathrm{C}} 2\right)$. Namely, ${ }^{\mathrm{C}} \mathrm{IM}$ can convert to products ${ }^{\mathrm{C}} \mathrm{P} 1$ and ${ }^{\mathrm{C}} \mathrm{P} 2$ through the $\mathrm{C}^{1}-\mathrm{C}^{2}$ bond break and the H-transferred step 

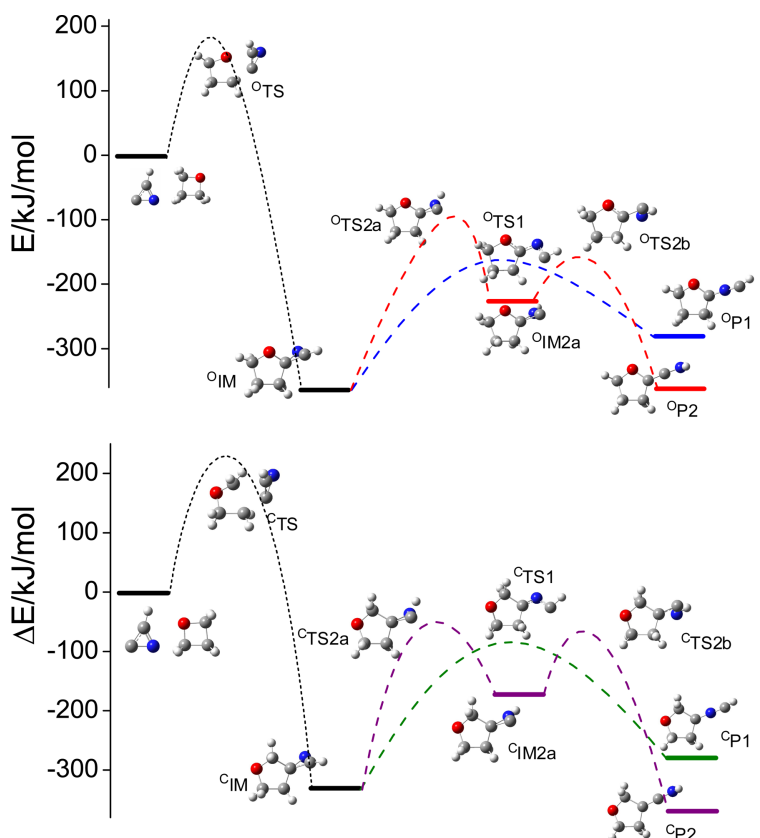

Figure 2. Reaction profiles for the pathways $\left({ }^{\mathrm{O}} 1\right),\left({ }^{\mathrm{O}} 2\right)$ (top), and pathways $\left({ }^{\mathrm{C}} 1\right),\left({ }^{\mathrm{C}} 2\right)$ (bottom) between azacyclopropenylidene and epoxypropane at the MP2/6-311+G* level of theory.
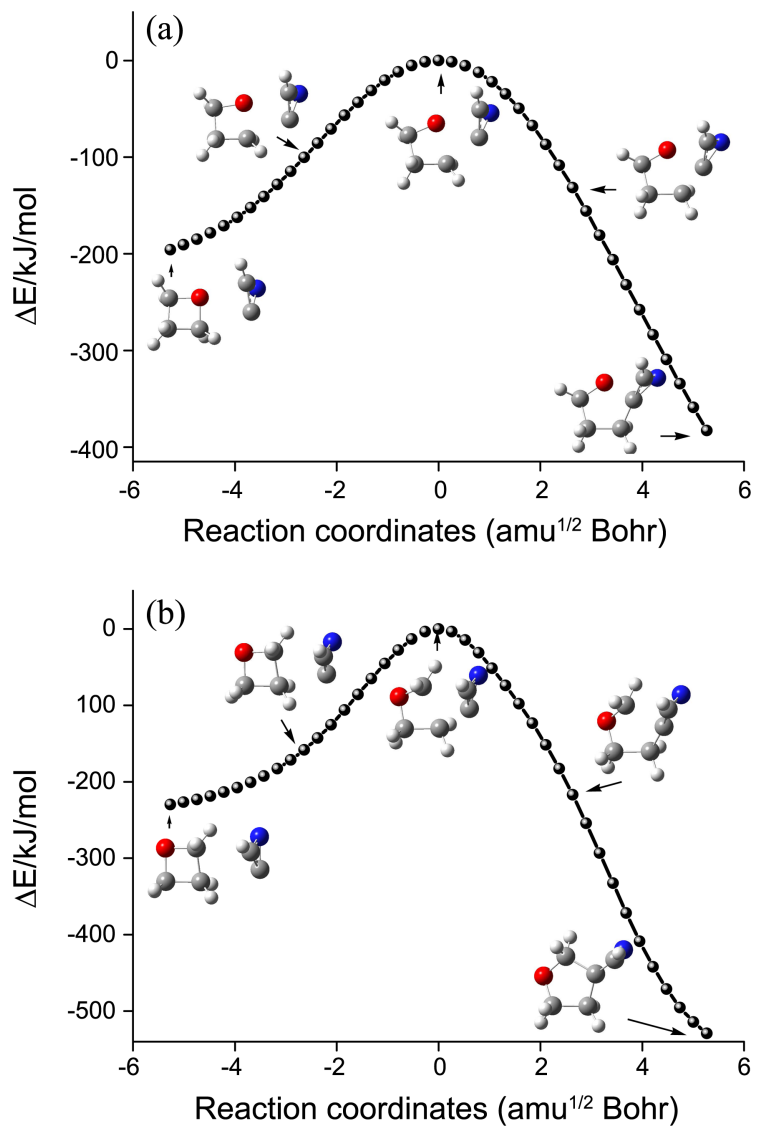

Figure 3. (a) IRC of ${ }^{\mathrm{O}} \mathrm{TS}$ and geometry evolution. (b) IRC of ${ }^{\mathrm{C}} \mathrm{TS}$ and geometry evolution.

plus the subsequent ring-opened step at the $\mathrm{C}-\mathrm{N}$ bond, respectively.
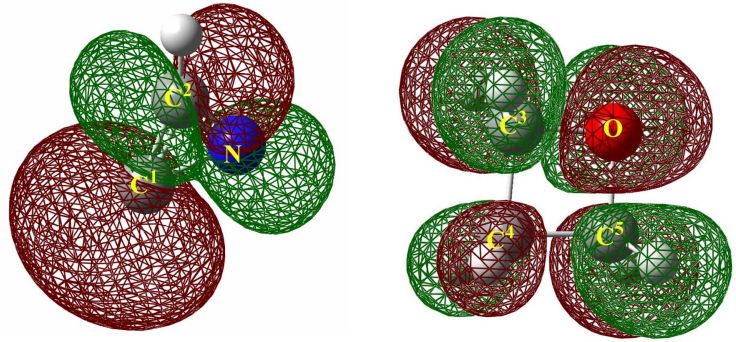

Figure 4. The calculated HOMO orbitals for azacyclopropenylidene and epoxypropane.

Pathway (1): Ring-Opened Process to form Carbene product. As mentioned above, the first step of pathway $\left({ }^{0} 1\right)$ is the process of the formation of ${ }^{\mathrm{O}} \mathrm{IM}$. Through the cleavage of the $\mathrm{C}^{1}-\mathrm{C}^{2}$ bond, the second step of pathway $\left({ }^{\mathrm{O}} 1\right)$ is that ${ }^{\circ} \mathrm{IM}$ convert to ${ }^{\circ} \mathrm{P} 1$ via $^{\circ} \mathrm{TS} 1$, where the barrier is $188.1 \mathrm{~kJ} /$ mol. The calculated only imaginary frequency of transition state ${ }^{\mathrm{O}} \mathrm{TS} 1$ is $365 \mathrm{icm}^{-1}$. IRC calculations have also been performed on the basis of the calculated ${ }^{\mathrm{O}} \mathrm{TS} 1$ to investigate the interactions between intermediate ${ }^{\mathrm{O}} \mathrm{IM}$ and product ${ }^{\mathrm{O}} \mathrm{P} 1$ in the pathway $\left({ }^{\mathrm{O}} 1\right)$ process.

As shown in Figure 1, for the angle of $\mathrm{C}^{1} \mathrm{NC}^{2}$ in ${ }^{\mathrm{O}} \mathrm{TS} 1$, it increases continuously along with the reaction. At the same time, the bond distance of $\mathrm{C}^{1}-\mathrm{C}^{2}$ increases along with the reaction process, implying the breakage of the three-membered ring involving $\mathrm{C}^{1} \mathrm{NC}^{2}$.

In ${ }^{\circ} \mathrm{P} 1$, all the non-hydrogen atoms are located in the same plane approximately. The $\mathrm{N}$ atom adopts $s p^{2}$ hybridization and the bond length of $\mathrm{C}^{1}-\mathrm{N}$ is $1.270 \AA$, which is shorter than the normal $\mathrm{C}=\mathrm{N}$ double bond. On the other hand, the distance of $\mathrm{N}-\mathrm{C}^{2}(1.254 \AA)$ is shorter than the normal N-C single bond. As for the $\mathrm{C}^{2}$ atom, it has a pair of lone electrons, making the ${ }^{\mathrm{O}} \mathrm{P} 1$ exhibit the carbene characters. Meanwhile, as described above, all of the electrons in ${ }^{\mathrm{O}} \mathrm{IM}$ are coupled, making it has relative stability even though there exists ring-tension in ${ }^{\mathrm{O}} \mathrm{IM}$. Therefore, from the thermodynamics viewpoint, ${ }^{\mathrm{O}} \mathrm{P} 1$ is not a stable product. Here, the calculated relative energy for ${ }^{\circ} \mathrm{P} 1$ is $-263.5 \mathrm{~kJ} / \mathrm{mol}$, which is higher about $86.6 \mathrm{~kJ} / \mathrm{mol}$ than that of ${ }^{\mathrm{O}} \mathrm{IM}$. Similarly, the calculated relatvie energy of ${ }^{\mathrm{C}} \mathrm{P} 1(-252.8 \mathrm{~kJ} / \mathrm{mol})$ is higher than that of ${ }^{\mathrm{C}} \mathrm{IM}(-323.0 \mathrm{~kJ} / \mathrm{mol})$. Therefore, ${ }^{\mathrm{C}} \mathrm{P} 1$ is not the most stable species along the pathway $\left({ }^{\mathrm{C}} 1\right)$.

Pathway (2): H-Transferred and Ring-Opened Process to form Allene Product. The second step and the third step of pathway $\left({ }^{\mathrm{O}} 2\right)$ is the $\mathrm{H}$-transferred process to form spiro intermediate ${ }^{\mathrm{O}} \mathrm{IM} 2 \mathrm{a}$, and the ring-opened process to form allene product ${ }^{\mathrm{O}} \mathrm{P} 2$, respectively.

The second step of pathway $\left({ }^{\mathrm{O}} 2\right)$ is the hydrogen transfer from $\mathrm{C}^{2}$ atom to the adjacent $\mathrm{N}$ atom, resulting in the conversion of ${ }^{\mathrm{O}} \mathrm{IM}$ into ${ }^{\mathrm{O}} \mathrm{IM} 2 \mathrm{a}$ via ${ }^{\mathrm{O}} \mathrm{TS} 2 \mathrm{a}$. IRC calculations have been performed on the basis of the calculated ${ }^{\circ} \mathrm{TS} 2 \mathrm{a}$ and ${ }^{\mathrm{O}}$ TS2b in the pathway $\left({ }^{\mathrm{O}} 2\right)$ process. Here, the calculated barrier is $278.9 \mathrm{~kJ} / \mathrm{mol}$ and the imaginary frequency of ${ }^{\mathrm{O}} \mathrm{TS} 2 \mathrm{a}$ is $1321 \mathrm{i} \mathrm{cm}^{-1}$. In details, as shown in Figure 1, the distance of $\mathrm{C}^{2}-\mathrm{H}^{1}$ in ${ }^{\mathrm{O}} \mathrm{TS} 2 \mathrm{a}$ has been elongated to $1.266 \AA$, and the dis- tance of $\mathrm{N}-\mathrm{H}^{1}$ reachs to $1.201 \AA$, indicating that 
the $\mathrm{H}^{1}$ atom can transfer from $\mathrm{C}^{2}$ atom to $\mathrm{N}$ atom.

Like ${ }^{\mathrm{O}} \mathrm{IM},{ }^{\mathrm{O}} \mathrm{IM} 2 \mathrm{a}$ is also a spiro intermediate. However, its bond between $\mathrm{C}^{2}$ and $\mathrm{N}$ atoms is a single bond, whereas it is a double bond in ${ }^{\mathrm{O}} \mathrm{IM}$. Therefore, there are two unpaired electrons in $\mathrm{C}^{2}$ atom. In other words, ${ }^{\mathrm{O}} \mathrm{IM} 2 \mathrm{a}$ possesses carbene characters, which is active and can convert into a more stable configuration.

The third step of pathway $\left({ }^{\mathrm{O}} 2\right)$ is the ring-opened process to form allene product ${ }^{\mathrm{O}} \mathrm{P} 2$. Through the cleavage of the $\mathrm{C}^{1}$ $\mathrm{N}$ bond, ${ }^{\mathrm{O}} \mathrm{IM} 2 \mathrm{a}$ converts into ${ }^{\mathrm{O}} \mathrm{P} 2$ via ${ }^{\mathrm{O}} \mathrm{TS} 2 \mathrm{~b}$, where the barrier is $54.3 \mathrm{~kJ} / \mathrm{mol}$. The calculated one imaginary frequency of transition state ${ }^{\circ} \mathrm{TS} 2 \mathrm{~b}$ is $410 \mathrm{i} \mathrm{cm}{ }^{-1}$. As shown in Figure 1, the bond distance of $\mathrm{C}^{1}-\mathrm{N}$ in ${ }^{\mathrm{O}} \mathrm{TS} 2 \mathrm{~b}$ elongates and the angle of $\mathrm{C}^{1} \mathrm{C}^{2} \mathrm{~N}$ increases along with the reaction process, implying the breakage of the three-membered ring involving $\mathrm{C}^{1} \mathrm{C}^{2} \mathrm{~N}$.

In ${ }^{\circ} \mathrm{P} 2$, the bond length of $\mathrm{C}^{1}-\mathrm{C}^{2}$ is $1.321 \AA$, which falls in the range of the intermediate between $\mathrm{C}=\mathrm{C}$ and $\mathrm{C} \equiv \mathrm{C}$ bond lengths. Similarly, the bond length of $\mathrm{C}^{2}-\mathrm{N}(1.246 \AA)$ is in the middle of $\mathrm{C}=\mathrm{N}$ and $\mathrm{C} \equiv \mathrm{N}$ bonds. The three atoms, $\mathrm{C}^{1}, \mathrm{C}^{2}$, and $\mathrm{N}$ atoms, are almost in the same line (angle of $\mathrm{C}^{1} \mathrm{C}^{2} \mathrm{~N}$ is $168.7^{\circ}$ ). Therefore, ${ }^{\circ} \mathrm{P} 2$ has the typical structural feature of allene. Like ${ }^{\mathrm{O}} \mathrm{IM}$, all of the electrons in ${ }^{\mathrm{O}} \mathrm{P} 2$ are coupled as well. There is a three-membered ring in ${ }^{\mathrm{O}} \mathrm{IM}$, and allene in ${ }^{\mathrm{O}} \mathrm{P} 2$, both of those two structures are unstable factors for a compound. Therefore, ${ }^{\mathrm{O}} \mathrm{IM}$ and ${ }^{\mathrm{O}} \mathrm{P} 2$ should have similar stability. Along the reaction profiles of pathway $\left({ }^{\mathrm{O}} 1\right)$ and $\left({ }^{\mathrm{O}} 2\right),{ }^{\mathrm{O}} \mathrm{IM}$ is the most stable species, which is exothermic with the value of $350.1 \mathrm{~kJ} / \mathrm{mol}$ compared with those of the reactants. The enery of ${ }^{\mathrm{O}} \mathrm{IM}$ is merely lower by $3.0 \mathrm{~kJ} / \mathrm{mol}$ than that of ${ }^{\mathrm{O}} \mathrm{P} 2$, which illustrates the similar stability of ${ }^{\mathrm{O}} \mathrm{IM}$ and ${ }^{\mathrm{O}} \mathrm{P} 2$. Similarly, ${ }^{\mathrm{C}} \mathrm{IM}$ and ${ }^{\mathrm{C}} \mathrm{P} 2$ also have similar stability. Somewhat different with reaction profile of pathways $\left({ }^{\mathrm{O}} 1\right)$ and $\left({ }^{\mathrm{O}} 2\right)$, the ${ }^{\mathrm{C}} \mathrm{P} 2$, instead of ${ }^{\mathrm{C}} \mathrm{P} 1$, is the most stable species along the pathways $\left({ }^{\mathrm{C}} 1\right)$ and $\left({ }^{\mathrm{C}} 2\right)$.

\section{Conclusions}

In this study, the reaction mechanism between azacyclopropenylidene and epoxypropane has been systematically investigated employing the MP2/6-311+G* level of theory. It is found that there are four pathways named $\left({ }^{\mathrm{O}} 1\right),\left({ }^{\mathrm{O}} 2\right)$, $\left({ }^{\mathrm{C}} 1\right)$, and $\left({ }^{\mathrm{C}} 2\right)$ to form four ultimate products ${ }^{\mathrm{O}} \mathrm{P} 1,{ }^{\mathrm{O}} \mathrm{P} 2,{ }^{\mathrm{C}} \mathrm{P} 1$ and ${ }^{\mathrm{C}} \mathrm{P} 2$, respectively. For the reaction of azacyclopropenylidene insertion into O-C bond in epoxypropane, the first step of the reaction is the formation of the common intermediate ${ }^{\mathrm{O}} \mathrm{IM}$. The barrier height of the rate-determining step in reaction pathways $\left({ }^{\circ} 1\right)$ and $\left({ }^{\circ} 2\right)$ are 203.0 and $278.9 \mathrm{~kJ} /$ mol, respectively. It's more difficult for azacyclopropenylidene to insert into $\mathrm{C}-\mathrm{C}$ bond in epoxypropane than into O-C bond. Therefore, the reaction pathway $\left({ }^{\mathrm{O}} 1\right)$ is the most favorable channel from the kinetic viewpoint. On the other hand, the overall trend of stabilized energies of products is: ${ }^{\mathrm{C}} \mathrm{P} 2(-364.2 \mathrm{~kJ} / \mathrm{mol})>{ }^{\mathrm{O}} \mathrm{P} 2(-347.1 \mathrm{~kJ} / \mathrm{mol})>{ }^{\mathrm{O}} \mathrm{P} 1(-263.5$ $\mathrm{kJ} / \mathrm{mol})>{ }^{\mathrm{C}} \mathrm{P} 1(-252.8 \mathrm{~kJ} / \mathrm{mol})$. Therefore, the most favorable product ${ }^{\mathrm{C}} \mathrm{P} 2$ should be confirmed from the thermodynamical viewpoint.
Acknowledgments. This work is supported by NSFC (21003082, 21303093), the project of Shandong Province Higher Educational Science and Technology Program (J13LM06), and the State Key Laboratory of Environmental Chemistry and Ecotoxicology, Research Center for EcoEnvironmental Sciences, Chinese Academy of Sciences (KF2013-05).

\section{References}

1. Joăo, B. P.; Da, S.; Mozart, N. R. Int. J. Quantum. Chem. 1992, 2, 215.

2. Francisco, J. A.; Richardson, S. L. J. Chem. Phys. 1994, 9, 7707.

3. Botschwina, P.; Horn, M.; Seeger, S.; Flugge, J. Mol. Phys. 1993, 1,191 .

4. Botschwina, P.; Schulz, B.; Horn, M.; Matuschewski, M. Chem. Phys. 1995, 190, 345.

5. Suzuki, S.; Yamamoto, H.; Ohishi, M.; Kaifu, N.; Ishikawa, S.; Hirahara, Y.; Takano, S. Astrophys J. 1992, 392, 551.

6. Matthews, H. E.; Irvine, W.; Freiberg, P.; Brown, R. D.; Godfrey, P. D. Nature 1984, 310, 125.

7. Aoki, K.; Ikuta, S.; Murakami, A. Chem. Phys. Lett. 1993, 3, 211.

8. Aoki, K.; Ikuta, S.; Nomura, O. J. Chem. Phys. 1993, 9, 7661.

9. Irvine, W. M. Adv. Space Res. 1995, 3, 35.

10. Lee, B. Chem. Phys. Lett. 1998, 1-2, 171.

11. Saito, S.; Kawaguchi, K.; Yamamoto, S.; Ohishi, M.; Suzuki, H.; Kaifu, N. Astrophys. J. 1987, 317, L115.

12. Bell, M. B.; Avery, L. W.; Feldman, A. Astrophys. J. 1993, 417, L37.

13. Yamamoto, S.; Saito, S.; Kawaguchi, K.; Kaifu, N.; Suzuki, H.; Ohishi, M. Astrophys. J. 1987, 317, L119.

14. Kim, K.; Lee, B.; Lee, S. Chem. Phys. Lett. 1998, 297, 65.

15. Lee, S. Chem. Phys. Lett. 1997, 1-2, 69.

16. Ohishi, M.; Kaifu, N.; Kawaguchi, K.; Murakami, A.; Saito, S.; Yamamoto, S.; Ishikawa, S. I.; Fujita, Y.; Shiratori, Y.; Irvine, W. M. Astrophys. J. 1989, 345, L83.

17. Bell, M. B.; Feldman, P. A.; Travers, M. J.; McCarthy, M. C.; Gottlieb, C. A.; Thaddeus, P. Astrophys. J. 1997, 483, L61.

18. McGonagle, D.; Irvine, W. M. Astron. Astrophys. 1996, 310, 970.

19. McCarthy, M. C.; Gottlieb, C. A.; Cooksy, A. L.; Thaddeus, P. J. Chem. Phys. 1995, 18, 7779.

20. Goldberg, N.; Fiedler, A.; Schwarz, H. J. Phys. Chem. 1995, 42, 15327.

21. Aoki, K.; Ikuta, S.; Nomura, O. J. Chem. Phys. 1993, 5, 3809.

22. Sun, F.; Kosterev, A.; Scott, G.; Litosh, V.; Curl, R. F. J. Chem. Phys. 1998, 20, 8851.

23. Hung, P. Y.; Sun, F.; Hunt, N. T.; Burns, L. A.; Curl, R. F. J. Chem. Phys. 2001, 20, 9331.

24. Rice, J. E.; Schaefer, H. F. J. Chem. Phys. 1987, 12, 7051.

25. Seidl, E. T.; Schaefer, H. F. J. Chem. Phys. 1992, 6, 4449.

26. Sung-Woo, P.; Sungyul, L. Bull. Korean Chem. Soc. 2002, 11, 1553 .

27. Natalia, I.; Xinchuan, H.; Timothy, J. L. J. Chem. Phys. 2011, 135, 244310.

28. Kassaee, M. Z.; Musavi, S. M.; Jalalimanesh, N. J. Theor. Comput. Chem. 2008, 3, 367.

29. Kassaee, M. Z.; Ghambarian, M.; Musavi, S. M. Heteroatom Chem. 2008, 4, 377.

30. Jacek, K. J. Phys. Chem. A 2003, 107, 4717.

31. Maier, G.; Reisenauer, H. P.; Rademacher, K. Chem. Eur. J. 1998, 10, 1957.

32. Maier, G.; Bothur, A.; Eckwert, J.; Reisenauer, H. P. Chem. Eur. J. 1998, 10, 1964.

33. Balucani, N.; Alagia, L.; Cartechini, M.; Casavecchia, P.; Volpi, G. G.; Sato, K.; Takayanagi, T.; Kurosaki, Y. J. Am. Chem. Soc. 2000, 18, 4443. 
34. Nimlos, M. R.; Davico, G.; Geise, C. M.; Wenthold, P. G.; Lineberger, W. C.; Blanksby, S. J.; Hadad, C. M.; Petersson, G. A.; Ellison, G. B. J. Chem. Phys. 2002, 9, 4323.

35. Frisch, M. J. et al., Gaussian 98; Gaussian Inc.: Pittsburgh, PA,
1998.

36. Thaddeus, P.; Gottlieb, C. A.; Mollaaghababa, R.; Vrtilek, J. M. J. Chem. Soc. Faraday Trans. 1993, 89, 2125. 